\title{
Reduction of insulin dose on changing diabetic children from standard to monocomponent insulins
}

\author{
N. K. GRIFFIN, M. A. SMITH, AND J. D. BAUM \\ John Radcliffe Hospital, Oxford
}

SUMMARY 21 diabetic children requiring $>50$ units of standard insulin daily were changed to a monocomponent insulin. During the 3 months before the change the insulin dose had risen significantly from a mean of 70 to a mean of 77 units daily. During the 3 months after the change the dose fell significantly to a mean of 53 units daily. This decrease in insulin requirement was associated with a general improvement in diabetic control. This was assessed clinically and measured in 10 children by an analysis of home urine tests and in 8 children by an analysis of 24-hour urine glucose excretion.

There have been significant advances in the manufacture of insulin. This has resulted in solutions that are free from proinsulin, insulin fragments, and other pancreatic contaminants (Schlichtkrull et al., 1972). Such insulins are variously described as proinsulin-free, single peak, or monocomponent insulins, depending on their degree of purity (Root et al., 1972).

The only clear advantage of these insulins is the avoidance or reversal of lipo-atrophy and local reactions at the site of injections (Galloway and Root, 1972; Teuscher, 1975). There have been reports of a reduction of the dose of insulin necessary for the maintenance of diabetic control on changing from standard to purified insulins. Reports of dose reduction has varied from 20 to $50 \%$ in different series, consisting mainly of adult diabetics (Bruni et al., 1973; Evans and Smith, 1976; Logie and Stowers, 1976).

We present data on 21 diabetic children requiring $>40$ units per day of standard insulins in whom a change to monocomponent insulin led to a decrease in insulin requirements and better diabetic control.

\section{Materials and methods}

21 children (13 girls and 8 boys) who were unable to achieve satisfactory diabetic control despite high and increasing insulin dosage were changed from

Department of Paediatrics, John Radcliffe Hospital, Oxford N. K. GRIFFIN, registrar

M. A. SMITH, medical laboratory scientific officer

J. D. BAUM, clinical reader standard to monocomponent insulins. The mean age of the group was 7.9 years (range 3-13) and the mean duration of their diabetes from diagnosis was $5 \cdot 2$ years (range 1.5-12). Their treatment before the change is shown in Table 1. All children in this group were changed to a monocomponent porcine insulin (Monotard)* given as a single daily injection. During the 3 months before and 3 months after the change in insulin, diabetic control was measured by an analysis of home urine tests using the Clinitest $\dagger$ 2-drop method (Belmonte et al., 1967), and the 24hour urinary glucose excretion measured on a collection made at home.

Table 1 The types and doses of standard insulins during the 3-month period preceding the change to monocomponent insulin

\begin{tabular}{lllll}
\hline Insulin regimen & & $\begin{array}{l}\text { Make of } \\
\text { insulin }\end{array}$ & $\begin{array}{l}\text { No. of } \\
\text { pa:ients }\end{array}$ & $\begin{array}{l}\text { Mean insulin } \\
\text { dose }\end{array}$ \\
\hline Lente & o.d. & Unspecified & 8 & 72 \\
Rapitard & o.d. & Novo & 7 & 78 \\
Actrapid+Rapitard & b.d. & Novo & 2 & 76 \\
Rapitard & b.d. & Novo & 1 & 88 \\
Semi-Lente & o.d. & Unspecified & 1 & 56 \\
Isophane+soluble & b.d. & Nordisk & 1 & 132 \\
PZI+ soluble & o.d. & Unspecified & 1 & 76 \\
\hline
\end{tabular}

Only 10 children were able to maintain their urine testing books in sufficient detail for an analysis of home urine tests to be made during the 3 months before and the 3 months after the change in insulin.

*Novo Insulins, Copenhagen.

†Ames Company, Slough. 
Although the number of tests performed each day by individual children varied, the total number of tests made by these children during the 3 months before the change was 2188 and the total number of tests for the 3 months after the change in insulin was 2089.

Only 8 children were able to provide a 24-hour urine collection for glucose analysis before and after the change. Six of these children were among the 10 who had maintained home urine testing books satisfactorily.

The first 24-hour urine collection for glucose excretion was obtained at a mean time of 6.5 days (range 1-13) before the change to monocomponent insulin. The 2nd 24-hour urine collection was performed 9 weeks (range 3.5-13) after the change to monocomponent insulin.

The glucose content of the 24-hour sample was measured with a glucose analyser which uses glucose oxidase (Analox Instruments). The results are expressed in grams of glucose/24 hours.

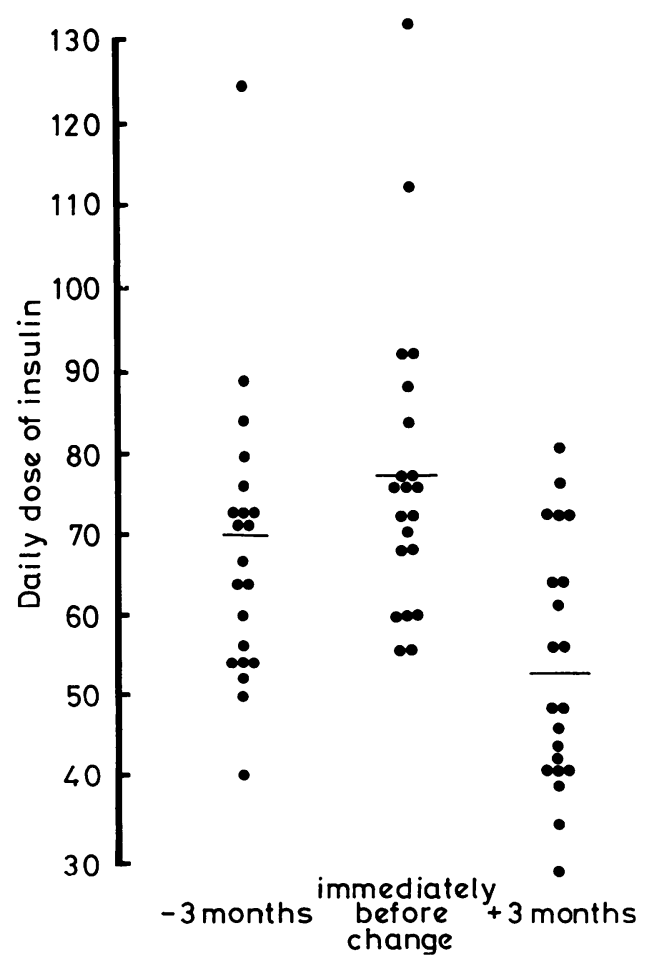

Figure The total daily dose of insulin for the 21 children rose significantly during the 3 months before the change (paired t test $P<0.001)$ and fell significantly during the 3 months after the change $(P<0.001)$.

\section{Results}

The insulin requirements in the 21 patients 3 months before the change in insulin, at the time of the change, $\frac{}{2}$ and 3 months after the change, are shown in the Figure. During the 3 months preceding the change $\frac{\bar{\omega}}{\frac{5}{7}}$ the daily dose of insulin rose from a mean of $70 \stackrel{\mathbb{}}{\Omega}$ units daily (range 40-124) to a mean of 77 units daily (range 56-132) $(\mathrm{P}<0.001$ using the paired $t$ test). In no case had the dose of insulin fallen over this period. During the 3 months after the intro- $\bar{\omega}$ duction of monocomponent insulin the mean requirement fell to 53 units daily (range 27-82) $(\mathrm{P}<0.001$ using the paired $t$ test). This represents an average fall of $31 \%$ in the insulin requirement. In only one child did the insulin requirement actually increase after the change to monocomponent $\vec{\omega}_{\mathrm{J}}$ insulin, rising from 60-64 units. The biggest single 0 fall was from 112 to 48 units (a fall of $64 \%$ ).

An analysis of the home urine tests from 10 children before and after the change in insulin was also made. Taking all the tests available for each child before and after the change and classifying any tests with $0-\frac{1}{2} \%$ glycosuria as 'good control' and $1-5 \% \frac{\overrightarrow{0}}{\overrightarrow{0}}$ glycosuria as 'poor control' a $2 \times 2 \chi^{2}$ table was drawn up for each patient. Five of the 10 children had significant improvements in their diabetic control with this method of evaluation $(P<0.001)$. One child had a $\chi^{2}$ value which just fell short of significance. The remaining 4 children had low $\chi^{2}$ values, indicating no significant improvements in control.

The urine tests for the two 3-month periods were also compared in terms of the number of tests showing zero glycosuria at any time. Using the paired $t$ test there was a significant increase in the total number of zero glycosuria tests after the change to monocomponent insulin $(\mathrm{P}<0 \cdot 01)$ (Table 2).

Table 2 A comparison of the total number of home urine tests using the 2-drop Clinitest method showing zero glycosuria during the 3 months before and 3 months after the change to monocomponent insulin. Using the paired t test there was a significant increase in the total number of zero glycosuria tests $(P<0.01)$.

\begin{tabular}{lll}
\hline Case & \multicolumn{2}{l}{ Total no. of zero glycosuria readings } \\
\cline { 2 - 3 } & $\begin{array}{l}\text { On conventional } \\
\text { insulin }\end{array}$ & $\begin{array}{l}\text { On monocomponent } \\
\text { insulin }\end{array}$ \\
\hline 1 & 95 & 116 \\
3 & 0 & 6 \\
5 & 12 & 137 \\
6 & 51 & 102 \\
7 & 92 & 132 \\
8 & 110 & 167 \\
9 & 19 & 50 \\
10 & 3 & 16 \\
11 & 11 & 22 \\
12 & 8 & 78.4 \\
Mean & $40 \cdot 1$ & \\
\hline
\end{tabular}


The number of zero glycosuria tests before breakfast was considered as an indication of overnight diabetic control. Using the paired $t$ test to compare the numbers 3 months before and 3 months after the insulin change there was a significant increase in the number of before-breakfast zero glycosuria tests after the change to monocomponent insulin $(P<0 \cdot 01$, Table 3$)$.

In 8 children 24-hour urine collections were available as a measure of diabetic control before and after the change (Table 4). The mean glucose excretion before the change was $137 \mathrm{~g} / 24 \mathrm{~h}$ (range 1-426 g/ $24 \mathrm{~h}$ ) which fell to a mean of $88 \mathrm{~g} / 24 \mathrm{~h}$ (range 0-237 g/ $24 \mathrm{~h})(\mathrm{P}<0.01$ using the paired $t$ test $)$. Only one of these 8 patients showed an increase in glycosuria. The high value for the mean glucose excretion both before and after the change was because 4 of the 8 children had gross glycosuria on standard insulins which fell but failed to achieve reasonable levels by the time of the 2 nd urine collection.

Table 3 Comparison of the number of zero glycosuria tests before breakfast during the 3 months before and after the change to monocomponent insulin. Using the paired t test there was a significant increase in the number of such tests after the change $(P<0.01)$.

\begin{tabular}{llc}
\hline Case & \multicolumn{2}{l}{ No. of zero glycosuria readings before breakfast } \\
\cline { 2 - 3 } & $\begin{array}{l}\text { On conventional } \\
\text { insulin }\end{array}$ & $\begin{array}{l}\text { On monocomponent } \\
\text { insulin }\end{array}$ \\
\hline 1 & 34 & 49 \\
3 & 0 & 3 \\
5 & 1 & 61 \\
6 & 34 & 77 \\
7 & 80 & 102 \\
8 & 37 & 52 \\
9 & 15 & 42 \\
10 & 2 & 3 \\
11 & 3 & 13 \\
12 & 4 & 18 \\
Mean & $21 \cdot 0$ & $42 \cdot 0$ \\
\hline
\end{tabular}

Table 4 24-hour urine glucose excretion before and 3 months after the change to monocomponent insulin. The reduction in glucose excretion is significant $(P<0.01)$ using the paired t test.

\begin{tabular}{lcc}
\hline Case & \multicolumn{2}{l}{ 24-hour glucose excretion $(\mathrm{g} / 24$ hours $)$} \\
\cline { 2 - 3 } & $\begin{array}{l}\text { On conventional } \\
\text { insulin }\end{array}$ & $\begin{array}{l}\text { On monocomponent } \\
\text { insulin }\end{array}$ \\
\hline 1 & $13 \cdot 1$ & $10 \cdot 4$ \\
2 & $426 \cdot 3$ & $237 \cdot 3$ \\
3 & $208 \cdot 4$ & $99 \cdot 6$ \\
4 & $1 \cdot 5$ & $2 \cdot 8$ \\
5 & $140 \cdot 2$ & $36 \cdot 0$ \\
6 & 133.6 & $186 \cdot 6$ \\
7 & 2.9 & $0 \cdot 2$ \\
8 & 169.1 & 133.3 \\
Mean & 136.9 & 88.3 \\
\hline
\end{tabular}

\section{Discussion}

The introduction of highly purified preparations of insulin represents an advance in the treatment of diabetics with lipo-atrophy at insulin injection sites. Many workers have observed a decrease in the insulin requirements of patients after a change to purified insulins (Evans and Smith, 1976; Logie and Stowers, 1976). This is in accord with the manufacturer's recommendations that, in patients requiring more than $\mathbf{4 0}$ units of insulin daily, the dose of insulin should be reduced by $20 \%$ at the time of the change (Novo Laboratories Ltd). The mean fall in insulin requirements of our patients was $31 \%$ during a 3-month period and some patients required further reductions subsequently. We had made a $10 \%$ reduction in the dose at the time of change to monocomponent insulin and subsequent reductions were made by the parents who had been warned of the likelihood of a reduced requirement. The parents judged this dose reduction by frequent home urine tests. In most cases the requirement began to fall after 2 weeks and continued to do so for a further 3-6 weeks. Many children had minor hypoglycaemic symptoms during this period and 2 children had major hypoglycaemic attacks, both suffering from early morning hypoglycaemic convulsions.

Comparative data on the quality of control achieved on changing from conventional to monocomponent insulins has been omitted in previous reports. Our results indicate that control was as good or better in most cases whether assessed clinically or by home urine tests or by 24-hour collections of urine for glucose excretion. Nevertheless the level of diabetic control achieved on monocomponent insulin was certainly not satisfactory at the time of reassessment in at least 4 of the children as judged by the persistently high 24-hour urinary glucose excretion.

Although the change of treatment is associated with the hazards of an uncertain reduction in the dose of insulin required, we do not feel that this constitutes a contraindication to the change provided that this likelihood is appreciated. We feel that all new diabetic children should be started on highly purified insulins and that established diabetic children should be changed on to highly purified insulins because of the reduced incidence of lipo-atrophy (Teuscher, 1975), the reported reduction in insulin antibody levels (Oakley, 1976), and because we believe that insulin should, as far as possible, be free from other protein contaminants as it is to be administered to the child for life.

Dr N. K. Griffin was supported by the Medical Research Fund of the Oxford Clinical School and Mrs A. Smith was in receipt of a grant from the British Diabetic Association. 


\section{References}

Belmonte, M. M., Sarkozy, E., and Harpur, E. R. (1967). Urine sugar determination by the two-drop Clinitest method. Diabetes, 16, 557-559.

Bruni, B., D'Alberto, M., Osenda, M., Ricci, C., and Turco, G. L. (1973). Clinical trial with monocomponent lente insulins. Diabetologia, 9, 492-498.

Evans, D. R., and Smith, C. S. (1976). Letter: Hazards of monocomponent insulins. British Medical Journal, 1, 1146.

Galloway, J. A., and Root, M. A. (1972). New forms of insulin. Diabetes, 21, 637-648.

Logie, A. W., and Stowers, J. M. (1976). Hazards of monocomponent insulins. British Medical Journal, 1, 879-880.

Oakley, N. W. (1976). Effect of 'fractionated' insulins on total plasma insulin binding capacity and insulin requirements in severe diabetics. Lancet. 1, 994-996.
Root, M. A., Chance, R. E., and Galloway, J. A. (1972). Immunogenicity of insulin. Diabetes, 21, 657-660.

Schlichtkrull, J., Brange, J., Christiansen, A. H., Hallund, O., Heding, L. G., and Jorgensen, K. H. (1972). Clinical aspects of insulin-antigenicity. Diabetes, 21, Supplement $2,649-656$.

Teuscher, A. (1975). The place of the 'monocomponent' insulins in the therapy of diabetes mellitus (in German). Schweizerische medizinische Wochenschrift, 105, 485-494.

Correspondence to Dr N. K. Griffin, The Hospital for Sick Children, Great Ormond Street, London WC1N 3JH.

Received 25 April 1978 